\title{
Sustainable operation analysis of the mining industry power supply system
}

\author{
Roman Klyuev ${ }^{1, *}$, Marat Tekiev ${ }^{2}$, Vadim Silaev², Igor Bosikov², Oksana Gavrina² \\ ${ }^{1}$ Moscow Polytechnic University, 38, B. Semenovskaya Str., Moscow, 107023, Russia \\ ${ }^{2}$ North-Caucasian Institute of Mining and Metallurgy (State Technological University), 44, Nikolaeva Str., Vladikavkaz, 362021, Russia
}

\begin{abstract}
The paper presents an analysis of operating currents and torques during self-starting of motors with a voltage of $6 \mathrm{kV}$ for cases of short circuit in the head feeders from the main step-down substation and in the feeders to the most distant substations of mining enterprises. For the network under consideration, the characteristic modes are: short circuit on the buses of shop substations. For the mining industry when selfstarting asynchronous motors with a squirrel-cage rotor and synchronous motors with asynchronous startup, the current multiplicity will be determined by the duration of the power failure (run-down duration). It has been established that the acceleration of motors during self-start will be somewhat slower than the usual start, since self-start begins at a speed of $0.89-0.94$ of the synchronous speed and a resistance torque is equal to $0.65-0.75$ of the maximum motor torque. The self-starting time of the motors is from $9 \mathrm{~s}$ to $42 \mathrm{~s}$. To ensure self-starting conditions in the most severe modes in mountain conditions, it is necessary to make changes to the protection settings presented in the work.
\end{abstract}

\section{Introduction}

At mining enterprises, an urgent and important task is the introduction of automatic start (self-start), for which it is necessary to analyze the characteristics of the "engine - technological unit" starting unit. The peculiarities of the operation of these units do not allow theoretically calculating the characteristics of selfstarting. Therefore, it is necessary to carry out experimental studies of start-up and run-down of units. It is in the course of calculating the actual self-starting currents according to the experimental characteristics and comparing them with the relay protection data that will make it possible to determine the possibility of selfstarting [1-3].

\section{Materials and methods}

The work uses modern methods for analyzing power supply systems using Excel and MathCad programs.

For the considered network, the characteristic modes are:

- short circuit on the buses of workshop substations. At the same time, the power supply interruption time is the sum of the short circuit disconnection time on the supply line and the ASR operation time at the substation [4-9];

- short circuit on the lines from the MSDS. The break time consists of the time for disconnecting the short

\footnotetext{
*orresponding author: kluev-roman@ rambler.ru
}

circuit on the buses from the MSDS and the time of the ATS at the workshop substation.

\section{Brief description of the power supply circuit for motors with a voltage of $6 \mathrm{kV}$}

Figure 1 shows the power supply circuit for $6 \mathrm{kV}$ motors from two sections of the main step-down substation (MSDS). The first and second sections of substation No. 11 are powered through the same lines equipped with identical protection. 4 motors with a capacity of $250 \mathrm{~kW}$ are powered from two sections of substation No. 11 .

Two sections of substation No. 12 are powered by 5 motors with a capacity of $320 \mathrm{~kW}$, one motor with a capacity of $400 \mathrm{~kW}$ [4-6]. Communication between substations No. 11 and No. 12 is carried out via two feeders F.50 and F.51.

\section{Determination of operating currents during self-start}

When self-starting asynchronous motors with a squirrelcage rotor and synchronous motors with asynchronous start-up, the current multiplicity will be determined by the duration of the power failure (run-down duration).

The total run-out time varies widely from $39 \mathrm{~s}$ to $291 \mathrm{~s}$. When calculating the conditions for self-starting, the experimental value of the total run-out is taken when the engine is disconnected from the network $(U=0)$ equal to the electromechanical constant of the unit under study. 


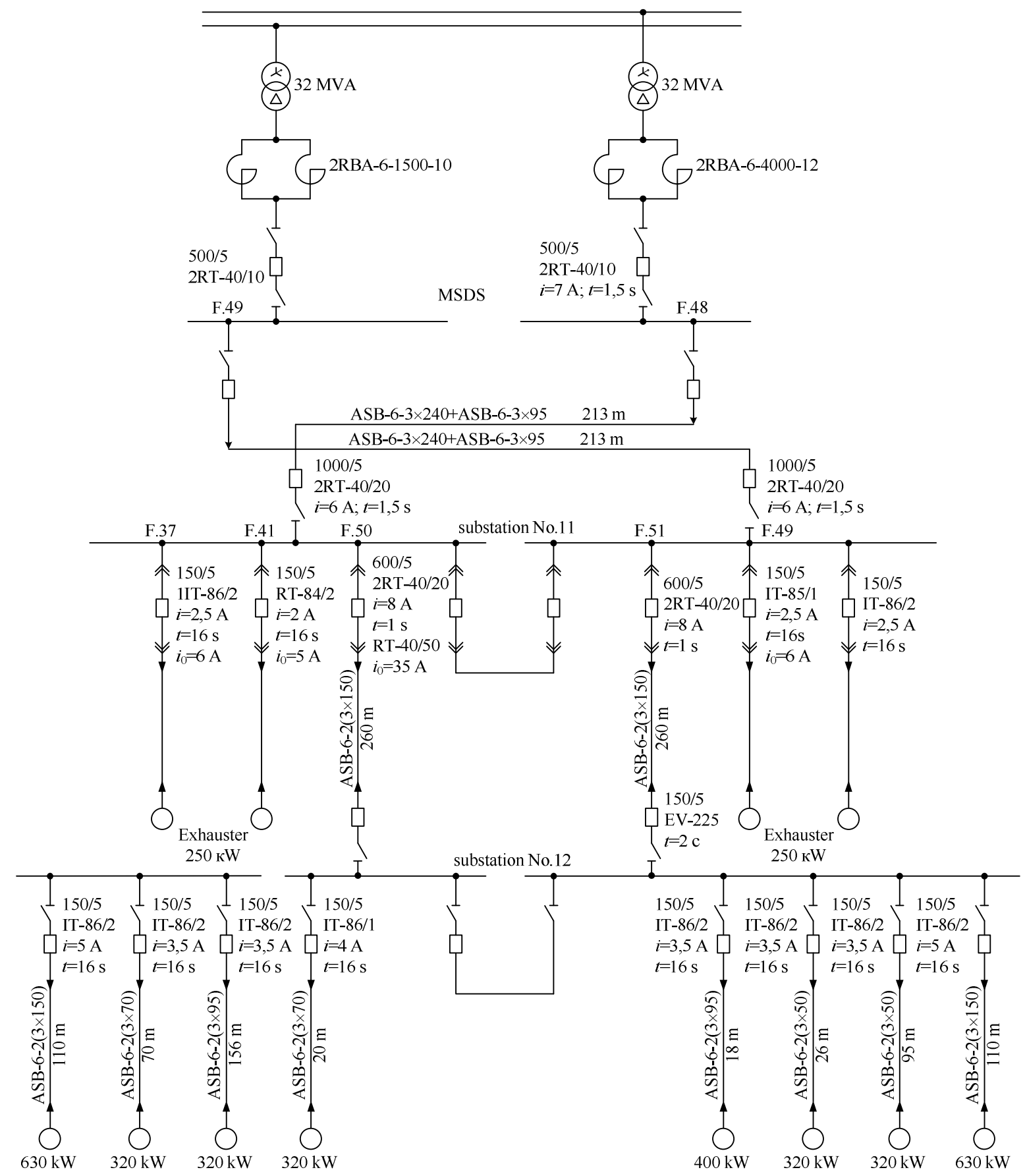

Fig. 1. Power supply circuit for $6 \mathrm{kV}$ motors from two sections of the MSDS.

$$
t_{\text {r.run-out }}=\frac{t_{\text {outage }}}{t_{\text {run-out }}} .
$$

Break time $t_{\text {outage }}$ in the power supply system of the motors will be the sum of the time of short-circuit currents cut-off $\left(t_{\mathrm{sc}}\right)$ at substations and the time of reserve input $\left(t_{\mathrm{ri}}\right)$ (the time of automatic switch-on of the reserve - ASR). Therefore, to determine the relative time, it is necessary to consider several modes of operation of the power supply after the action of the ASR.

To determine the operating currents and currents for setting the maximum current protection (MCP) of networks, let us consider the typical normal and emergency modes of self-starting [10-12].
Self-starting (ss) of four motors at substation No. 12 $(630 \mathrm{~kW}, 400 \mathrm{~kW}, 320 \mathrm{~kW}, 320 \mathrm{~kW})$ after disconnecting the feeder protection F.51 after $1 \mathrm{~s}$ and turning on the automatic transfer switch at substation No. 12 after $3 \mathrm{~s}$. Similarly for the F.50 feeder, the total time of an interruption in the power supply is: $t_{\text {outage }}=t_{\mathrm{sc}}+t_{\mathrm{ASR}}=1$ $+3=4$ s.

The relative run-out time ranges from 0.037 to 0.05 . Sliding along the coasting curves will be $0.096-0.11$. The multiplicity of the starting current during self-start is determined by the expression:

$$
k_{\mathrm{ss}}=\frac{1}{\sqrt{1+\left(\frac{s_{\mathrm{cs}}}{s}\right)^{2}}},
$$


where $s_{\mathrm{cs}}-$ critical slip (cs). For the engines under consideration, it varies in the range from 0.268 to 0.292 . Multiplicity of self-starting currents:

- blower with a power of $320 \mathrm{~kW}$ :

$$
k_{\mathrm{ss}}=\frac{6,4}{\sqrt{1+\left(\frac{0.292}{0.096}\right)^{2}}}=2 \text {; }
$$

- smoke exhausters with a power of 320 of $\mathrm{kW}$ and $630 \mathrm{~kW}$ :

$$
k_{\mathrm{SS}}=\frac{5,2}{\sqrt{1+\left(\frac{0.268}{0.11}\right)^{2}}}=1.97
$$

- blower with a power of $400 \mathrm{~kW}$ :

$$
k_{\mathrm{ss}}=\frac{7.2}{\sqrt{1+\left(\frac{0.268}{0.11}\right)^{2}}}=2.73 \text {. }
$$

Total self-starting current is $I_{\mathrm{ss} \Sigma}=37.2 \cdot 2+45.2 \cdot 2.73+71 \cdot 1.97+39 \cdot 1.97=412.3 \quad$ A. Total operating current of the feeder F.50: $I_{\mathrm{F} .50}=(71+37.1 \cdot 1) \cdot 0.8+175=261.5$ A. Feeder current F.50 with self-starting is $I_{\text {ss.F. } 50}=I_{\mathrm{ss} \Sigma}+I_{\mathrm{F} .50}=412.3+261.5=673.8$ A.

The operating current of the relay MCP of the feeder F.50 with the transformation ratio of the current transformer $(\mathrm{ct})$ is $k_{\mathrm{ct}}=120: I_{\mathrm{MCP}}=673.8 / 120=5.61 \mathrm{~A}$, which is less than setting current $(\mathrm{sc}) i_{\mathrm{sc}}=8 \mathrm{~A}$. The MCPF.50 is not activated when self-starting.

For the F.51 feeder, with self-starting of four motors of section 2 of substation No. 12, the self-starting currents will differ slightly (instead of a $400 \mathrm{~kW}$ motor, a $320 \mathrm{~kW}$ motor is connected).

Let us consider the self-starting of four motors of substation No. 12 and two motors of substation No. 11 when the MCP feeder F.48 is turned off (similar to F.49) after $1.5 \mathrm{~s}$ and the ATS at substation No. 11 is turned on after $2 \mathrm{~s}$. The power supply interruption time is $t_{\text {outage }}=$ 3.5 s. Relative run-down time is $0.04 \div 0.033$. Sliding along the coasting curves is $0.08 \div 0.095$. Multiplicity of starting current during self-start:

- blower with a power of $320 \mathrm{~kW}$ :

$$
k_{\mathrm{SS}}=\frac{6.4}{\sqrt{1+\left(\frac{0.292}{0.08}\right)^{2}}}=1.69 \text {; }
$$

- smoke exhausters with a power of $320 \mathrm{~kW}$ and 630 $\mathrm{kW}$ :

$$
k_{\mathrm{SS}}=\frac{5.2}{\sqrt{1+\left(\frac{0.268}{0.095}\right)^{2}}}=1.74 ;
$$

- blower with a power of $400 \mathrm{~kW}$ :

$$
k_{\mathrm{SS}}=\frac{7.2}{\sqrt{1+\left(\frac{0.268}{0.095}\right)^{2}}}=2.4 \text {; }
$$
kW:

$$
k_{\mathrm{SS}}=\frac{6.3}{\sqrt{1+\left(\frac{0.248}{0.06}\right)^{2}}}=1.48 .
$$

Self-starting current is $I_{\mathrm{ss}}=45.2 \cdot 2.4+39 \cdot 1.74+37.1 \cdot 1.69+32 \cdot 2=333.76 \quad$ A. The pperating (op) current of sections of substation No. 12 and substation No. 11 is $I_{\mathrm{op}}=(29.52+71+39+37.1)$ $0.8+2 \cdot 175=514.9 \mathrm{~A}$. The total self-starting current is $I_{\mathrm{ss} \Sigma}=333.76+514.9=848.64 \mathrm{~A}$. The operating current of the relay MCP feeder F.48 (F.49) at the transformation ratio of current transformer is $k_{\mathrm{ct}}=120$ : $I_{\mathrm{MCP}}=848.64 / 120=7.072 \mathrm{~A}$, which is less than the setting current $i_{\mathrm{sc}}=12.5 \mathrm{~A}$.

Self-start time is determined by the amount of excess torque (et):

$$
m_{\mathrm{et}}=m_{\mathrm{ns}}-m_{\mathrm{cs}},
$$

where $m_{n s}-$ torque (starting) when sliding;

$m_{c s}-$ slip moment.

Moments of resistance:

$m_{\mathrm{cs} 1}=0.05+(0.75-0.05) \cdot(1-0.06)^{2} \cdot m_{\text {nominal }}=0.6685$;

$m_{\mathrm{cs} 2}=0.05+(0.75-0.05) \cdot(1-0.11)^{2} \cdot m_{\text {nominal }}=0.6$.

The voltage in the network during self-starting will be significantly higher than that when starting from an initial speed due to an increase in the resistance of the motors.

$200 \mathrm{~kW}$ motor:

$x_{\text {motor }}=\frac{1}{k_{\mathrm{ss}}} \cdot \frac{S_{\text {base }}}{S_{\text {motor }}} \cdot\left(\frac{U_{\text {base }}}{U_{\text {nominal }}}\right)^{2}=371.6$.

$630 \mathrm{~kW}$ motor:

$x_{\text {motor }}=\frac{1}{1.74} \cdot \frac{100}{0.63} \cdot\left(\frac{6.3}{6.0}\right)^{2}=100.35$.

320 kW motor:

$x_{\text {motor }}=\frac{1}{1.69} \cdot \frac{100}{0.32} \cdot\left(\frac{6.3}{6.0}\right)^{2}=203.4$.

400 kW motor:

$x_{\text {motor }}=\frac{1}{1.74} \cdot \frac{100}{0.4} \cdot\left(\frac{6.3}{6.0}\right)^{2}=158.05$.

The total resistance of motors and loads at substations No. 12, No. 11 and at the MSDS is $x_{12}=15.19 ; x_{11}=9.028 ; x_{\text {гाпा }}=7.67$.

Voltage on the tires of the MSDS during self-start is $U_{\mathrm{MSDS}}=1.05 \cdot \frac{7.67}{7.67+0.757}=0.956$, where 0.757 system resistance, transformers and reactor.

Voltages on the buses of substation No. 11, motors with a power of $200 \mathrm{~kW}$ and buses of substation No. 12 are respectively:

$$
\begin{aligned}
& U_{11}=0.956 \cdot \frac{9.028}{9.028+0.02}=0.954 ; \\
& U_{200}=0.954 \cdot \frac{371.6}{371.6+0.0091}=0.954 ; \\
& U_{12}=0.954 \cdot \frac{15.198}{15.218}=0.953 .
\end{aligned}
$$

Voltages on the motors of substation No. 12 with a capacity of $630 \mathrm{~kW}, 320 \mathrm{~kW}$ and $400 \mathrm{~kW}$ : 


$$
\begin{aligned}
& U_{630}=0.953 \cdot \frac{100.35}{100.37}=0.9528 ; \\
& U_{320}=0.953 \cdot \frac{203.4}{203.42}=0.9529 ; \\
& U_{400}=0.953 \cdot \frac{158.05}{158.071}=0.9528 .
\end{aligned}
$$

Self-starting torques for motors with a power of 200 $\mathrm{kW}, 630 \mathrm{~kW}, 320 \mathrm{~kW}$ (2 motors - a blower and a smoke exhauster), $400 \mathrm{~kW}$ are respectively:

$$
\begin{aligned}
& m_{n s 200}=1.5 \cdot(0.954)^{2}=1.365 ; \\
& m_{n s 630}=1.1 \cdot(0.9528)^{2}=0.999 ; \\
& m_{n s 320}=1.4 \cdot(0.9529)^{2}=1.27 ; \\
& m_{n s 320}=1.1 \cdot(0.9529)^{2}=0.999 ; \\
& m_{n s 400}=1.5 \cdot(0.9528)^{2}=1.362 .
\end{aligned}
$$

Excessive moments of rotation according to expression (3) are respectively:

$$
\begin{aligned}
& m_{\mathrm{et} 200}=1.365-0.6=0.765 ; \\
& m_{\mathrm{et} 630}=0.999-0.6685=0.3305 ; \\
& m_{\mathrm{et} 320}=1.27-0.6685=0.6015 ; \\
& m_{\mathrm{et} 320}=0.999-0.6685=0.3305 ; \\
& m_{\mathrm{et} 400}=1.362-0.6685=0.6935
\end{aligned}
$$

Self-start time is:

$$
t_{\mathrm{ss}}=\frac{s}{m_{\mathrm{et}}} \cdot t_{\text {run-out }} .
$$

For engines of various powers, these are respectively:

$$
\begin{aligned}
& t_{\mathrm{ss} 200}=\frac{0.11}{0.765} \cdot 291=41.8 \mathrm{~s} \\
& t_{\mathrm{ss} 630}=\frac{0.06}{0.3305} \cdot 107=19.42 \mathrm{~s} \\
& t_{\mathrm{Ss} 320}=\frac{0.06}{0.6015} \cdot 80=7.98 \mathrm{~s} \\
& t_{\mathrm{Ss} 320}=\frac{0.06}{0.3305} \cdot 107=19.42 \mathrm{~s} \\
& t_{\mathrm{Ss} 400}=\frac{0.06}{0.6935} \cdot 107=9.26 \mathrm{~s}
\end{aligned}
$$

\section{Results and Discussion}

As can be seen from the calculation of self-starting, all motors of substation No. 12 are provided with selfstarting with a self-starting time somewhat longer than the normal starting time.

Motors with a power of $200 \mathrm{~kW}$ with a normal starting time of $40 \mathrm{~s}$ have a self-start time of $41.8 \mathrm{~s}$. During experimental measurements of the start-up and run-out time, the MCP of the engine turned off the engine $16 \mathrm{~s}$ after the start of the start-up, and restarting after 2-3 minutes of run-out led to a full acceleration of the engine in 24-26 with a total acceleration time of 40$42 \mathrm{~s}$.

Therefore, from all motors, it is necessary to change the overcurrent protection settings: increase the setting current at least to $2.5 \mathrm{~A}-3 \mathrm{~A}$, leaving the delay $16 \mathrm{~s}$. On other engines, the protection meets the self-starting conditions. Similar studies have been carried out at other enterprises [13-17]. The results are presented in the conclusions.

\section{Conclusion}

The analysis of operating currents and moments of rotation during self-starting for cases of short circuit at the head feeders from the gas transmission station and at the feeders to the most distant substations shows that self-starting of all motors, which, according to the technology, allow self-starting, is provided by the existing power supply system.

The acceleration of motors during self-start will be somewhat slower than the usual start, since self-start begins at a speed of $0.89 \div 0.94$ of the synchronous speed and a resistance moment equal to $0.65 \div 0.75$ of the maximum engine torque. The self-starting time of the motors is from $9 \mathrm{~s}$ to $42 \mathrm{~s}$.

MCP of all motors at self-starting currents does not have time to disconnect the motors from the electrical network, with the exception of the MCP feeder F.41 to the $200 \mathrm{~kW}$ exhaust gas engine. MCP of the feeder F.41 with a setting on the RT-84/2 relay for a current 2 A and a time of $16 \mathrm{~s}$ does not provide not only self-starting, but also direct start. The setting of the MCP feeder F.41 for current must be increased to $2.5 \mathrm{~A}$.

\section{References}

1. K.V. Litsin, S.N. Baskov, Automated technologies and production 5, 185-187 (2013)

2. V.V. Borodina, Electrical equipment: operation and repair 5, 66-68 (2010)

3. A.V. Bogdan, H. Alavi, A.S. Shakhanin, New Science: Problems and Perspectives 2, 54-57 (2017)

4. I. I. Bosikov, R. V. Klyuev, V. N. Khetagurov, I. M. Azhmukhamedov, Sustainable development of mountain territories 1, 77-83 (2021)

5. R. V. Klyuev, O. A. Gavrina, V. N. Khetagurov, S. G. Zaseev, B. Z. Umirov, Mining Informational and Analytical Bulletin 11-1, 135-145 (2020)

6. V. I. Golik, O. Z. Gabaraev, S. A. Maslennikov, Z. M. Khasheva, L. P. Shulgaty, The Social Sciences (Pakistan) 11, 4348- 4351 (2016)

7. V. I. Golik, Yu. I. Razorenov, V. S. Brigida, O. G. Burdzieva, Bulletin of the Tomsk Polytechnic University, Geo Assets Engineering 331(6), 175-183 (2020) 
8. N. S. Buryanina, Yu. F. Korolyuk, E. I. Maleeva, E. V. Lesnykh, Sustainable Development of Mountain Territories 3, 404-410 (2018)

9. P. V. Vasiliev, G. V. Stas, E. V. Smirnova, Proceedings of the Tula States University-Sciences of Earth 2, 45-58 (2016)

10. J. Daoud, D. Friedrich, Applied Thermal Engineering 151, 134-145 (2019)

11. K. Qu, T. Gong, J. Shao, Procedia Computer Science 166, 517-522 (2020)

12. Ch. Fang, L. Cui, Reliability Engineering \& System Safety 197 (2020)

13. M. I. Altshuller, Territory Neftegaz 6, 14-15 (2010)

14. E. Heylen, G. Deconinck, D. Hertem, Renewable and Sustainable Energy Reviews 97, 554-568 (2018)

15. V. Rexhepi, Energy Process 141, 418422 (2018)

16. S. Davidov, M. Pantoš, Energy 166, 886894 (2019)

17. W. Lee, B. Kang, J. Jung, Energy 161, 963-973 (2018) 